Uluslararası Mühendislik

\title{
Mekanik Tapalardaki Pandül ve Rotor Ağırlık Değişimlerinin Namlu Önü Emniyetine Etkilerinin İncelenmesi
}

\section{Investigation Of The Effects Of Changes In Weights Of Pallets And Rotors In Mechanical Fuzes On Muzzle Safety}

\author{
Zühtü Onur Pehlivanlı ${ }^{\text {iD }, \text { Serhad Yıldız }}{ }^{2}$ iD \\ ${ }^{1}$ Kırıkkale Üniversitesi, Mühendislik Fakültesi, Metalurji ve Malzeme Mühendisliği Bölümü,71450,Kırlkkale, TÜRKIYE \\ ${ }^{2}$ Kırıkkale Üniversitesi, Fen Bilimleri Enstitüsü, Savunma Teknolojileri Anabilim Dalı,71450,Kırıkkale,TÜRKIYYE
}

$\ddot{O} \mathbf{z}$

$\mathrm{Bu}$ çalışmada, mühimmatın atış öncesinde, atış anında ve atış sonrasından fonksiyon gösterdiği süreye kadar, personel güvenliğini sağlayan topçu ve havan güvenlik ve kurma mekanizmalarında yer alan, pandül ve rotor ağırlıklarının kurulma süresine yani namlu önü emniyet mesafesine olan etkileri araştırılmıştır. Deneysel olarak yapılan bu çalışmada dönüsüz havan mühimmatlarında kullanılan havan tapasındaki pandüllerin ve dönülü topçu mühimmatlarında kullanılan topçu tapasındaki rotorların ağırlıkları değiş̧irilerek güvenlik ve kurma mekanizmalarının kurulma süreleri incelenmiş̧ir. Pandüllerde \%7-38'e kadar, rotorlarda ise \%9-17'ye kadar ağırlık düşürülmüştür. Yapılan çalışma sonucunda pandüllerin ağırlıklarındaki azalışın tapa kurulma sürelerini azalttığı ancak rotorlarda ağırlık düşüşünün tapa kurulma süresini arttırdığı sonucuna varılmıştır.

\section{Anahtar Kelimeler}

"Tapa, Güvenlik ve Kurma Mekanizmasl (GKM), Pandül, Rotor"

\begin{abstract}
In this study, the effects of pallet and rotor weights to the arming time, in other words muzzle safety, were investigated. Pallets and rotors are both located in the artilley and mortar SAD mechanisms which are used to provide safety of personnel before, during and after firing of the ammunition. In this experimental study, weights of the pallets have been altered for the smoothbore-mortar ammunition while similar changes have been applied to the weights of the rotors for the rifled-artillery ammunition and then, arming time of the SAD mechanisms were examined according to these changes. The weights have been reduced up to $7-38 \%$ for the pallets whereas up to $9-17 \%$ for the rotors. Eventually, it was concluded that arming time has been reduced by decreasing the weight of the pallets, however, arming time has been increased by applying the similar weight reduction operation to the rotors.
\end{abstract}

Key Words

"Fuzes, Safe And Arm Device (S\&AD), Pallet, Rotor" 


\section{Giriş}

Teknolojik olarak hızla gelişen dünyada, silah sistemleri de sürekli geliştirilmekte ve değişmektedir. Malzeme teknolojisindeki gelişmeler, yazılım alanında geliştirilen sistemler ve kimyasal patlayıcılar üzerinde yapılan çalışmaların bütünü silah sistemlerinde önemli gelişmeler kaydedilmesine yol açmıştır. Silah sistemlerindeki bütün çalışmalar sistemin güvenliğini en üst düzeye çıkartacak; aynı zamanda etkinliğini ve güvenilirliğini arttıracak şekilde kurgulanmaktadır.

Uçak bombaları, roketler, topçu mühimmatı, havan mühimmatı, uçaksavar mühimmatı, deniz mühimmatı, el bombaları, mayınlar, torpidolar vb. askeri silahlar ve mühimmatlar üretiminden görevini icra edinceye kadar ki ömür döngüsü boyunca tüm güvenlik ve emniyet şartlarını sağlayacak güvenlik sistemleri ve mekanizmaları bulundurmak zorundadırlar. Bu güvenlik mekanizmalarından en önemlisi de tapalardır. Tapalar, mühimmatın aktivasyonunun hangi zamanda ve nerede gerçekleşmesi kararını verecek olan ve aynı zamanda namlu önü emniyeti de dahil tüm emniyet mekanizmalarını ve patlayıcı zinciri ve bileşenlerini üzerinde bulunduran, mühimmata baş veya dip kısmından bağlanan güvenlik mekanizmalarıdır. Tapa sistemlerinde namlu önü emniyet mesafesi de tapalar içerindeki güvenlik ve kurma mekanizmalarıyla sağlanmaktadır. Güvenlik ve kurma mekanizmasının en önemli görevi mühimmatın namludan çıktıktan sonra dönü ve g kuvvetlerinin etkisiyle belli bir mesafeye gelene kadarki geçen sürede patlayıcı zincirini aynı eksen üzerine getirmektir.

Cooper and Bobetsky (2003), güvenli kurma mesafesini arttırmak için bazı çalışmalar yapmıştır. Birinci çalışmada çinko döküm olan rotoru alüminyum rotor olarak dizayn etmiştir. Böylece alüminyum rotorun kütlesi \%56 azalmış buna bağlı olarak da kurulma süresi \%32 artmıştır. İkinci çalışmada ise pandülün ağırlığı \%61 arttırılmış ve buna bağlı olarak da kurulma süresi \%40 artmıştır. Ayrıca bu iki çalışma birleştirilerek yani alüminyum rotor ve ağırlığı arttırılmış pandül birlikte kullanılmış ve kurulma süresinin \%85 arttığı görülmüştür. Kurulma mesafeleri ise modifiyesiz standart rotor ve pandül birlikte kullanıldığında 250 feet olarak, alüminyum rotor ve ağırlığı arttırılmış pandül birlikte kullanıldığında ise 463 feet olarak ölçülmüştür.

Lewis (2003), güvenlik kurma mesafesini arttırmak için rotorun ağırlık merkezi aynı kalmak şartıyla, rotor üzerinde boşaltma yaparak rotoru hafifletmiş ve normalden iki kat daha ağır pandül ile birlikte kullanmıştır (Mofn GKM). Çalışmada kurulma süresi; devir testi, dinamik analiz ve Abaqus analiz yazılımı ile ölçülmüştür.

Geaney, Leng and Rhode (2014), bilgisayarlı deney tasarımı ve sonlu elemanlar istatiksel analiz metotlarıyla 40 mm M549 A1 ve M550 tapalarındaki güvenlik kurma mekanizmalarındaki değişikliklerle kurma zamanını ölçmüş ve kurulma süresini etkileyen temel etkenleri belirlemiştir. Bilgisayarlı deney tasarımı ve sonlu elemanlar istatiksel analiz sonuçları M549 A1 ve M550 GKM kurulma süreleri için benzer sonuçlar vermiş ve kurulma süresi değişimindeki tüm faktörlerin pandül-hareket nakil çarkı etkileşiminden kaynaklandığı tespit edilmiştir.

Ardak and Phate (2014), yaptığı çalışmada örnek iki dişli sisteminde pandülün süreye olan etkisini incelemiştir. Birinci dişli sisteminde pandül kullanmamış ve sistemde $330^{\circ}$ döndürülmek istenen dişli, 19,93 saniyede istenilen konuma gelmiştir. Bu sürede hareket nakil çarkı ise 11.000 tur atmıştır. İkinci dişli sisteminde ise pandül kullanmış olup sistemde $330^{\circ}$ döndürülmek istenilen dişli, 3600 saniyede istenilen konuma gelmiştir. Bu sürede pandül ile birlikte hareket eden hareket nakil çarkı 62 tur atmıştır. Çalışma sonucunda pandülün süreyi arttırdığı ve hareket nakil çarkını yavaşlattığı sonucuna varılmıştır.

$\mathrm{Bu}$ verilen çalışmalar literatürde tapalarla ilgili olarak yapılan önemli çalışmalar olmakla birlikte, tapalar ve tapalardaki güvenlik ve kurma mekanizmaları üzerine daha pek çok sayıda çalışma yapıldığı görülmektedir. Literatürde yapılan çalışmalar 1şığında bu çalışmalarda; dönüsüz havan tapası içerisinde yer alan pandüllerin ve dönülü topçu tapasında kullanılan rotorların ağırlıklarının tapa kurulma süresine yani namlu önü emniyet mesafesine olan etkilerinin incelenmesi planlanmıştır.

Bu kapsamda, havan tapaları için pandül, topçu tapalarında ise rotor ele alınarak tapa kurulma sürelerindeki değişimler deneysel olarak incelenmiştir.

\section{Materyal ve Metot}

\subsection{Malzeme}

Rotor malzemesi olarak, C36000-H02 pirinç malzeme kullanılmış olup malzemenin özellikleri Tablo 1'de verilmiştir. Standart ölçülere sahip 5 adet rotor CNC (Computer Numeric Control) tezgâhında talaş kaldırılarak üretilmiştir. Daha sonra hazırlanan standart rotorlardan 4 adedinin, rotor ağırlığının kurulma süresine olan etkisini incelemek amacıyla ağırlıkları azaltılmıştır. Pandül malzemesi olarak, C35300-H06 pirinç malzeme kullanılmış olup malzeme özellikleri Tablo 1'de verilmiştir. 7 adet pandül de 
rotorlarda olduğu gibi CNC tezgâhı kullanılarak imal edilmiştir. Daha sonra hazırlanan standart pandüllerden 6 adedinin, pandül ağırlığının kurulma süresine olan etkisini incelemek amacıyla ağırlıkları azaltılmıştır.

Tablo 1. Pandül ve rotor imalatında kullanılan malzemelerin fiziksel özellikleri

\begin{tabular}{cccccc}
\hline Malzeme & $\begin{array}{c}\text { Yoğunluk } \\
\left(\mathbf{k g} / \mathbf{m}^{\mathbf{3}}\right)\end{array}$ & $\begin{array}{c}\text { Çekme } \\
\text { Mukavemeti } \\
(\mathbf{M P a})\end{array}$ & $\begin{array}{c}\text { Akma } \\
\text { Mukavemeti } \\
(\mathbf{M P a})\end{array}$ & $\begin{array}{c}\text { Elastisite } \\
\text { Modülü } \\
(\mathbf{M p a})\end{array}$ & $\begin{array}{c}\text { Sertlik } \\
\text { (RockwellB) }\end{array}$ \\
\hline $\begin{array}{c}\text { C36000- } \\
\text { H02 }\end{array}$ & 8,498 & 345 & 140 & 96.527 & 78 \\
$\begin{array}{c}\text { C35300- } \\
\text { H06 }\end{array}$ & 8,470 & $338-586$ & $117-427$ & 117.211 & 75 \\
\hline
\end{tabular}

\subsection{Deney numunelerinin hazırlanmast}

Rotor ve pandüllerin ağırlık değişimlerini görmek için öncelikle 3D CAD programları yardımıyla bilgisayar ortamında rotorun katı modeli hazırlanmış ve yine aynı programlar yardımıyla rotor ve pandüllerin ağırlık merkezi belirlenmiştir. Daha sonra bu ağırlık merkezinde küçük değişikliklere müsaade edilecek (fonksiyonu etkilemeyecek) şekilde rotor üzerine farklı çap ve sayıda boşaltma yapılmış ve boşaltılan deliklerin koordinatları ve referans alınan noktaları kaydedilmiştir. Daha sonra hazırlanmış olan standart rotor numunelerine Henri Hauser Bienne marka koordinat matkap tezgâhı yardımıyla istenilen koordinatlardaki delikler açılarak kütle boşaltma işlemi yapılmıştır. Standart ve kütle boşaltma işlemi sonucundaki rotor numuneleri Şekil 1'de, özellikleri ise Tablo 2'de gösterilmiştir.

Pandül numunelerinin ağırlıklarını düşürmek için ise Fritz Werner Werkzeugmaschinen marka profil tezgahı kullanılmıştır. 3D CAD programını yardımıyla belirlenen kısımlar profil tezgahında talaş kaldırılarak istenilen ölçülere getirilmiştir. Ağırlık düşürme işlemi sonucunda elde edilen pandüller Şekil 2'de, özellikleri ise Tablo 3 'te gösterilmiştir.

Tüm pandül ve rotorların ağırlıkları, Sartorius FC06BBE-SX marka elektronik hassas terazi kullanılarak 1/1000 ölçüm hassasiyetle ölçülmüştür.

Tablo 2. Rotor deney numuneleri ve özellikleri

\begin{tabular}{ccccccc}
\hline $\begin{array}{c}\text { Numune } \\
\text { Kodu }\end{array}$ & $\begin{array}{c}\text { Standart } \\
\text { Rotor } \\
\text { Ağırlığı } \\
(\mathbf{g r})\end{array}$ & $\begin{array}{c}\text { Ağırlığı } \\
\text { Düşürülmüşs } \\
\text { Rotor } \\
\text { Ağırlığı } \\
(\mathbf{g r})\end{array}$ & $\begin{array}{c}\text { GKM } \\
\text { Kurulma } \\
\text { Süresi } \\
(\mathbf{m s})\end{array}$ & $\begin{array}{c}\text { GKM } \\
\text { Kurulma } \\
\text { Devri } \\
(\mathbf{d} / \mathbf{d a k})\end{array}$ & $\begin{array}{c}\text { Oluşturulan } \\
\text { Delik Çapları } \\
(\mathbf{m m})\end{array}$ & $\begin{array}{c}\text { Boşaltılan } \\
\text { Kütle } \\
\text { Miktarı }\end{array}$ \\
\hline RT0 & 18,878 & 18,878 & 800 & 3000 & - & 0 \\
RT1 & 18,872 & 17,219 & 830 & 3000 & $1 \times 5$ & 1,653 \\
RT2 & 18,868 & 16,755 & 872 & 3000 & $2 \times 4$ & 2,113 \\
RT3 & 18,879 & 16,489 & 883 & 3000 & $3 \times 4$ & 2,39 \\
RT4 & 18,881 & 15,693 & 1100 & 3000 & $4 \times 3$ & 3,188 \\
\hline
\end{tabular}



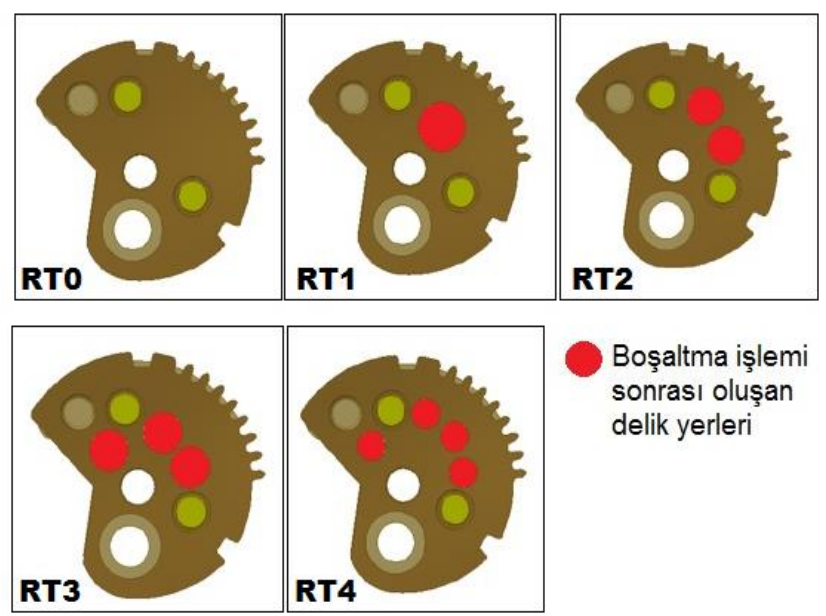

Şekil 1. Deneysel çalışmada kullanılan standart (RT0) ve modifiye rotorlar

Tablo 3. Pandül deney numuneleri ve özellikleri

\begin{tabular}{|c|c|c|c|c|}
\hline $\begin{array}{c}\text { Pandül } \\
\text { Numunesi }\end{array}$ & $\begin{array}{c}\text { Standart } \\
\text { Pandül } \\
\text { Ağırlı̆̆ı } \\
\text { (gr) }\end{array}$ & $\begin{array}{c}\text { Ăğırlı̆̆ı } \\
\text { Düşürüllmüş } \\
\text { Pandül } \\
\text { Ağırlığı } \\
\text { (gr) }\end{array}$ & $\begin{array}{c}\text { Kurulma } \\
\text { süresi } \\
(\mathrm{ms})\end{array}$ & $\begin{array}{c}\text { Boşaltılan } \\
\text { Kütle } \\
\text { Miktarı } \\
\text { (gr) }\end{array}$ \\
\hline $\mathrm{P} 0$ & 2,843 & 2,843 & 901 & 0 \\
\hline $\mathrm{P} 1$ & 2,830 & 2,637 & 815 & 0,193 \\
\hline $\mathrm{P} 2$ & 2,841 & 2,591 & 795 & 0,25 \\
\hline P3 & 2,844 & 2,547 & 775 & 0,297 \\
\hline P4 & 2,839 & 2,370 & 739 & 0,469 \\
\hline P5 & 2,829 & 2,103 & 701 & 0,726 \\
\hline P6 & 2,846 & 1,754 & 642 & 1,092 \\
\hline
\end{tabular}

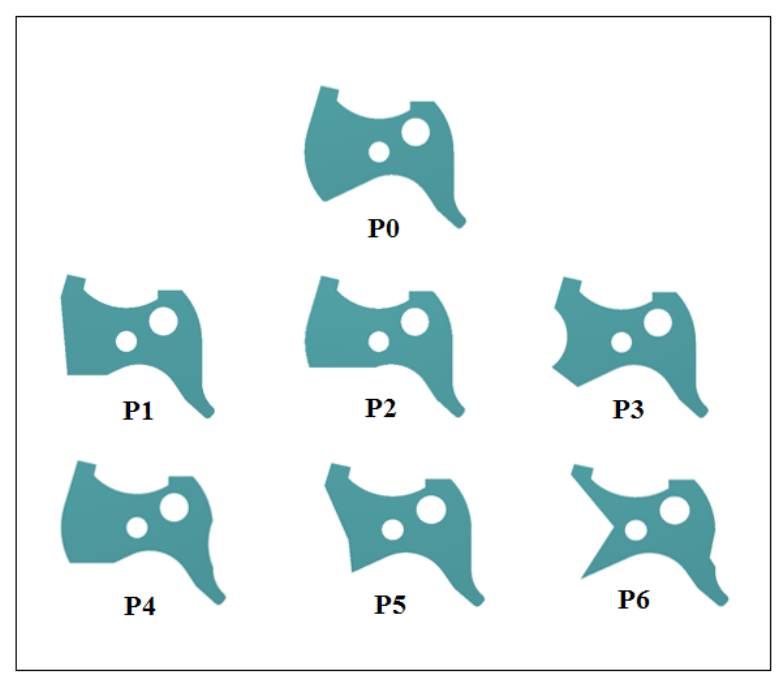

Şekil 2. Deneysel çalışmada kullanılan standart (P0) ve modifiye pandüller 


\section{Bulgular}

Hazırlanan pandül numunelerinin kurulma sürelerinin belirlenmesi için pandüller, incelenen havan tapasına monte edilerek kurulma süreleri ölçülmüş̧ür. Havan tapasının kurulma süresini ölçmek için Şekil 3 'te görülen zaman test cihazı kullanılmıştır. Zaman test cihazında; tapa tezgaha bağlandıktan sonra mühimmatın gidiş yönü aksine oluşan atalet kuvvetini simule eden kol aşağı indirilerek rotorun hareket etmesini önleyen millerin yay kuvvetlerini yenerek aşağı inmesini sağlar böylece rotor kendisini tutan millerin çekilmesiyle depolanmış yay kuvveti sayesinde harekete başlar. Hareket başladığı an titreşim de başlar ve tezgâh titreşim sona erene kadar süreyi devam ettirir. Titreşimi baz alarak çalışan zaman test cihazı titreşimin bittiği anı, yani tapanın kurulma süresini verir.

Aynı şekilde modifiyeli rotorlar aynı topçu tapası güvenlik kurma mekanizmasına monte edilerek kurulma işlemi gerçekleştirilmiştir. Tapanın kurulma işlemi için Şekil 4'te görülen devir tezgahı kullanılmıştır. Devir tezgâhı elektrik motoru, redüktör ve takometreden oluşmakta olup, maksimum devri 4000 d/dak'dır. Devir tezgahına topçu tapası güvenlik kurma mekanizması bağlandıktan sonra kurulma süreleri ölçülmüştür. Kurulma sürelerinin ölçülmesinde lazer renk sensörü kullanılmıştır.

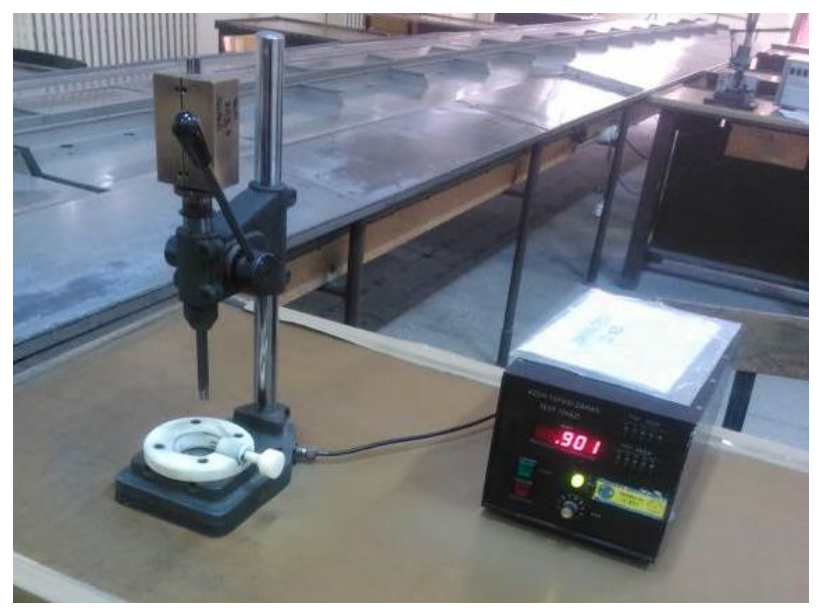

Şekil 3. Havan Zaman Test Cihazı

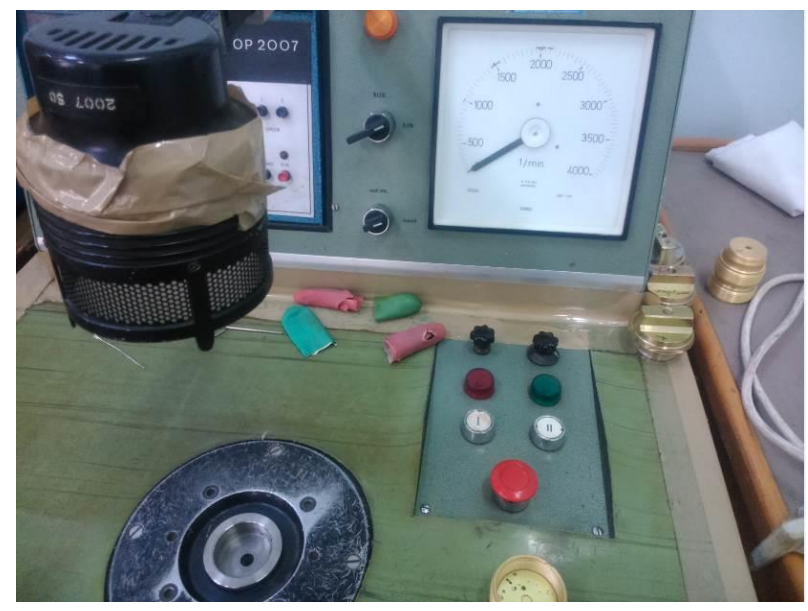

Şekil 4. Devir Tezgahı

\section{Tartışma ve Sonuç}

Havan Tapasında kullanılan pandüllerden 7 adet pandül numunesi alınmış ve bu pandüller aynı havan tapasına monte edilerek kurulma süreleri zaman test cihazında ölçülmüştür ve kaydedilmiştir. Bu kapsamda incelenen pandüllerin kurulma sürelerinde \pm 20 ms (mili saniye) sapma olduğu gözlemlenmiştir. Daha sonra bu pandüllerden 6 tanesi yukarıda açıklanan ağırlık değiş̧irme işlemine tutulmuştur ve sonrasında havan tapasına tekrar monte edilerek kurulma süreleri test cihazında ölçülmüş ve kaydedilmiştir. Elde edilen deney sonuçları karşılaştırmalı olarak Şekil 5 ’te verilmiştir. 


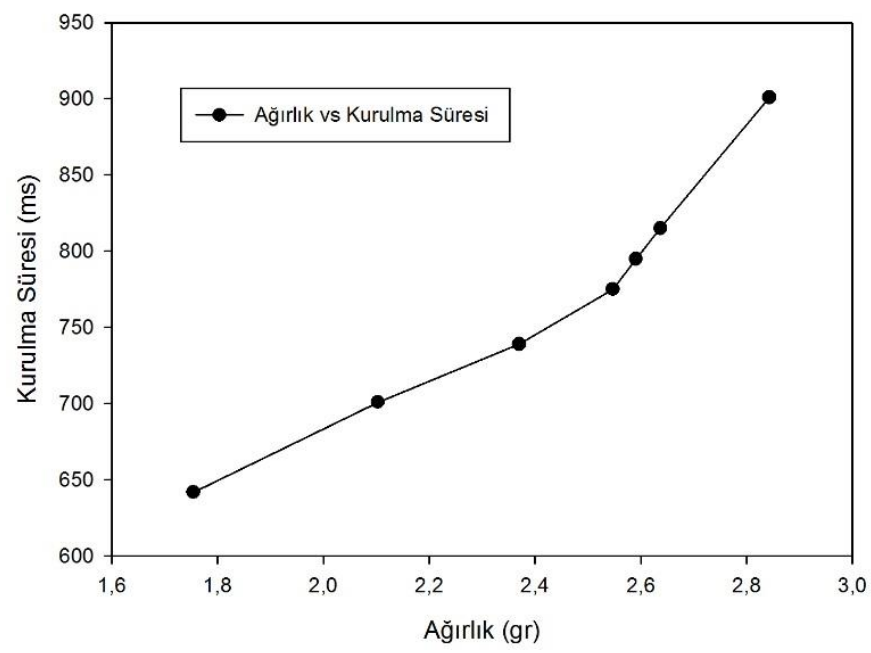

Şekil 5. Kurulma süresinin pandül ağırlığıyla değişimi

Topçu tapasının güvenlik kurma mekanizmasında kullanılan rotorlardan, ağılıkları $\pm 0,013$ gr sapma olan 5 adet rotor seçilmiştir. Seçilen bu rotorlar daha sonra aynı standart güvenlik kurma mekanizmasına monte edilmiş ve devir tezgâhında 3000 devir/dakikadaki kurulma süreleri lazer renk sensörü ile ölçülmüştür. Ölçülen kurulma süreleri ve ağırlık arasındaki ilişki Şekil 6'da verilmiştir.

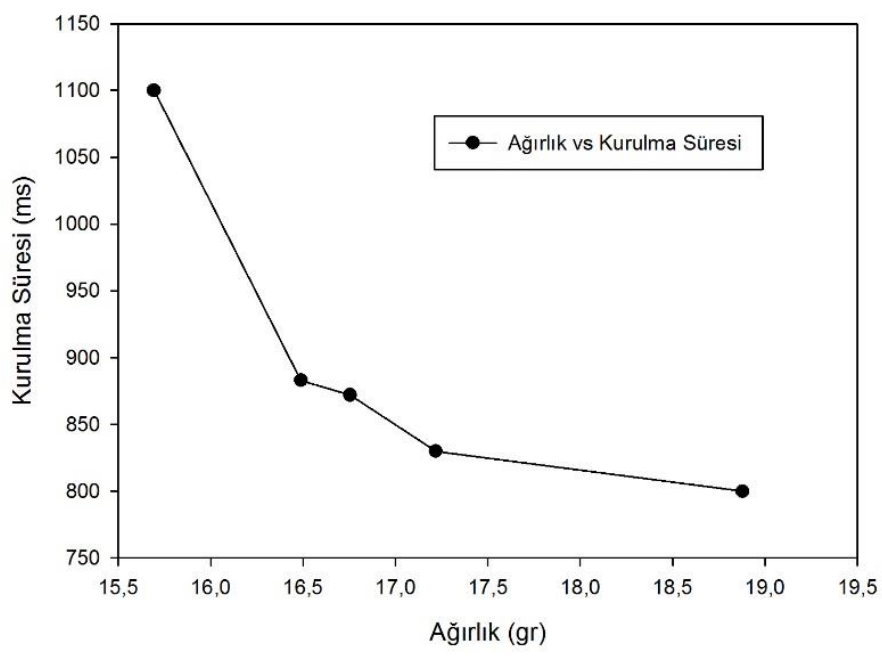

Şekil 6. Kurulma süresinin rotor ağırlı̆̆ıyla değişimi

\subsection{Rotor ăğırlı̆̆ının kurulma süresine etkisi}

Rotor ağırlı̆̆ı-kurulma süresi ilişkisini incelemek için dönülü topçu tapasında kullanılan, kütle boşaltması yapılarak hazırlanmış 5 farklı rotor numunesi üzerinde yapılan deneysel çalışma sonuçları incelendiğinde rotor ağırlığı azaldıkça kurma süresinin arttığı görülmüştür. Bu sonuç detonatörü muhafaza eden ve patlayıcı zincirinin aynı eksene gelmesini sağlayan rotorun bu dinamik hareketini dönme ekseninden kaçık pozisyonlamasıyla ve mühimmatın dönüsüyle alan mekanizmalarda geçerlidir. Rotor ağırlığının artması namlu önü emniyeti açısında incelendiğinde ise rotor ağıllı̆̆ı düştükçe namlu önü emniyet mesafesinin de azaldığı görülmüştür.

\subsection{Pandül ă̆ırlı̆̆ının kurulma süresine etkisi}

Pandül ağırlığı-kurulma süresi ilişkisini incelemek için 7 farklı pandülün, fonksiyonunda ve çalışma şeklinde değişiklik olmayacak şekilde kütle boşaltması yapılmıştır ve pandül ağırlığı üzerinde yapılan deneysel çalışma sonuçları incelendiğinde, kurulma süresinin pandül ağırlığıyla doğrusal değiştiği görülmüştür. Tapaların emniyetini sağlayan güvenlik kurma mekanizmalarında sönümleyici etki yapan pandülün ağırlığı arttıkça mekanizmanın tüm hareketi boyunca geçen süre yani kurulma süresinin arttığı görülmüştür. Kurulma süresinin artması direk olarak namlu önü emniyet mesafesini de artırmaktadır. 
Sonuç olarak rotor ve pandül ağırlıklarının tapa kurulma sürelerine olan etkilerini incelemek üzere yapılan deneysel çalışma sonuçları, rotor ağırlığı azaldıkça kurulma süresinin de rotor ağırlığına bağlı olarak doğrusal olarak azaldığı ancak pandül ağırlığında ki azalışın kurulma süresiyle ters orantılı olarak değiştiğini göstermiştir. Bu durum bize, yapılacak tapa tasarımlarında seçilecek rotor ve pandül ağırlığının dolayısıyla seçilecek malzemenin ne kadar önemli olduğunu ifade etmektedir. Çünkü kurulma süresi sayesinde namlu önü emniyet mesafesi belirlenmektedir. Namlu önü emniyet mesafesi personel ve donanım emniyeti için hayati öneme sahiptir. Bu sonuçlar 2003 yılında Keith Lewis ve Edward F. Cooper tarafından yapılan çalışmalarla benzer sonuçlar göstermiştir ve yapılan deneysel çalışmaların sonuçlarını destekleyici niteliktedir.

\section{Referanslar}

Ardak, M. B., \& Phate, M. R. (2014). Mathematical Modeling and Computer Simulation For Mechanical Timer Runway Escapement Mechanism, Mechanical Engineering Department, Pune University, Padmabhooshan Vasantadada Patil Institute of Technology Pune, India.

Burke, P., \& Pergolizzi, T. (2008). XM1156 Precision Guidance Kit (PGK), Information Briefing for 52nd Annual Fuze Conference.

Campion, B. (2007). Nexter Munition, 51st Annual NDIA Fuze Conference, Nashville.

Cooper, E. F., \& Bobetsky, A. (2003). L3 Communications Bt fuze products division 47th DIA Annual Fuze Conference.

Deeds, M., \& Cox, A. (2009). Variable Acceleration Profiling and Characterization of S\&A Escapement Mechanisms Indian Head Division Naval Surface Warfare Center Indian Head, MD NDIA Fuze Conference.

Finch, C. (2003). Naval Surface Warfare Center Dahlgren 47th Annual Fuze Conference "Enhancing Weapon Performance”.

Fowler, S. E. (1999). Safety and Arming Device Design Principles, Naval Air Warfare Center Weapons Division, China Lake, CA. Geaney, J . (2009). Rdecom, NDIA Fuze Conference Orlando, Florida.

Hendershot, J. (2012). Navy Fuze S\&T and Acquisition Strategy (NAVSEA), 56th Annual NDIA Fuze Conference, Baltimore.

Kautzsch, K. (2008). Junghans Microtec, 52nd NDIA Annual Conference.

Kautzsch, K. B. (2007). Junghans Feinwerktechnik GmbH \& Co. KG, 51st Annual Fuze Conference, Nashville, TN.

Lewis, K. (2003). Naval Surface Warfare Center Dahlgren 47th Annual Fuze Conference “Enhancing Weapon Performance”.

Lowen, G. G., \& Tepper, F. R. (1978). Dynamics of Pin Pallet Runaway Escapement.

Mil- Std- 1316E. (1998). Design Criteria Standard Fuze Design, Safety Ctriteria For, Department of Defense, United States of America.

Overman, D. L. (1971). Analysis Of M125 Booster Mechanism.

Rhode, M., Geaney, J., \& Leng, D. (2014). RDECOM, 57th NDIA Annual Fuze Conference.

STANAG 2916. (1989). Nose Fuze Contours And Matching Projectile Cavities For Artillery And Mortar Projectiles, NATO Standardization Agency (NSA).

Tapa Dizaynında Esaslar. (1975). Mke Mühimmat Fabrikası Etüd ve Geliştirme Kısım Müdürlüğü.

Ulamış, F. (2012). Mühimmatlar için elektronik zaman ayarlı ateşleyici sistem tasarım, Elektrik Elektronik Anabilim Dalı Yüksek Lisans tezi.

Wagner, J. (2006). Junghans Feinwerktechnik GmbH \& Co. KG, 50th Annual NDIA Fuze Conference, Norfolk, VA.

Will, B. (2007). Naval Surface Warfare Center (NAVSEA), 51st NDIA Fuze Conference, Nashville, Tennessee.

Yaşar, H. (1979). Mühimmatın Esasları. 